\title{
Clostridium difficile Infection in Pediatric Inflammatory Bowel Disease Patients in the Era of Molecular Diagnostics and Advanced Therapeutics
}

Dhiren Patel 1,2,3,4, Eric McGrath ${ }^{1,2,3,5}$, Namir Al-Ansari ${ }^{1,2,3,4}$, Ron Thomas ${ }^{1,3}$, Mohammad El-Baba 1,2,3,4

${ }^{1}$ Wayne State University School of Medicine, Detroit, MI

${ }^{2}$ Children's Hospital of Michigan, Detroit, MI

${ }^{3}$ Carman and Ann Adams Department of Pediatrics, Detroit, MI

${ }^{4}$ Division of Pediatric Gastroentrology, Hepatology and Nutrition

${ }^{5}$ Division of Pediatric Infectious Diseases

Corresponding author: Dhiren Patel, MD. Cardinal Glennon Children's Medical Center at Saint Louis University. 1465 S. Grand Blvd. St.Louis,MO,63104 Phone: 314.577.5647 Email: dhiren.patel@health.slu.edu

Citation: Dhiren Patel et.al (2017). Clostridium difficile Infection in Pediatric Inflammatory Bowel Disease Patients in the Era of Molecular Diagnostics and Advanced Therapeutics. Int J Ped \& Neo Heal. 1:4, 105-115

Copyright: (C) Dhiren Patel This is an open-access article distributed under the terms of the Creative Commons Attribution License, which permits unrestricted use, distribution, and reproduction in any medium, provided the original author and source are credited.

Received August 09, 2017 Accepted August 21, 2017, Published August 31, 2017

\section{Abstract}

Objective

Increased prevalence of Clostridium difficile infection (CDI) in pediatric Inflammatory Bowel Disease (IBD) has been reported, primarily using stool toxin assay. Stool Polymerase Chain Reaction (PCR) testing for CDI has replaced toxin assay due to the higher sensitivity and specificity. No pediatric study has reviewed exclusive PCR testing to report CDI in IBD patients. Objective of this study is to analyze demographic and clinical features in IBD patient's age 18 years and less, including Crohn's disease (CD) or ulcerative colitis (UC) who had CDI diagnosed by PCR at a tertiary children's hospital. Materials and Methods

IBD patients with CDI were identified retrospectively from October, 2010 - June, 2014. Patients' demographics, IBD characteristics and treatment, treatment of CDI, response and recurrence were recorded. Comparisons between groups were analyzed using non-parametric tests.

Results

Forty three $\mathrm{CD}$ and $27 \mathrm{UC}$ patients with CDI were identified. CDI presentation was abdominal cramping, diarrhea with or without bleeding. Higher percentage of CDI in CD 28/43 (65\%) did not have gross bleeding compared to $11 / 27(41 \%) \mathrm{UC}(\mathrm{p}=0.05$ ). Significantly higher proportion of CD versus UC patients was on Infliximab. Majority of patients $(64 / 70 ; 91 \%)$ received metronidazole.

Conclusions

CDI should be considered while evaluating pediatric patients with IBD flare up. Absence of blood in stool does not rule out CDI. CD patients on infliximab had a significantly higher proportion of CDI in our study. Most patients responded to metronidazole in both groups. Future studies are needed to evaluate risk of CDI associated with biologic therapy.

Key Words Polymerase Chain Reaction, Pediatrics, Inflammatory Bowel Disease, Clostridium Difficile Infection, Crohn's Disease, Ulcerative Colitis 


\section{Introduction}

Clostridium difficile is gram-positive, cytotoxin producing anaerobic bacterium that may cause colonization or infection in the human host. An increased prevalence of Clostridium difficile infection (CDI) in pediatric Inflammatory Bowel Disease (IBD) has been reported in various studies (1-3), primarily diagnosed by stool toxin assay $(1,4)$. Although some risk factors for CDI have been reported consistently in adult IBD study including recent antibiotic use and recurrent hospitalizations (5), there are no consistent risk factors reported in pediatric studies. The epidemiology of C. difficile infection in children has changed dramatically in last decade. Report from the Centers for Disease Control and Prevention conclude that patients with no previously documented risk factors are now at increasing risk of CDI with higher morbidity and mortality (6). A recent study has suggested that prevalence of CDI is higher in children with IBD than those without IBD ( 24.7 $\%$ vs. $8.9 \%$ ) and the inflammatory disease activity is significantly greater in CDI patients than uninfected patients (7) .

All pediatric studies thus far reported in the literature are based on detection of stool toxins although some of them have included cases diagnosed by both toxin and Polymerase Chain Reaction (PCR). To our knowledge, no study has exclusively reviewed the use of the PCR technique to detect pediatric CDI in IBD patients. In many institutions, PCR testing of stool for CDI has replaced the toxin assay due to the higher sensitivity and specificity (8).

Our primary aim was to analyze demographic and clinical features of CDI in IBD patients aged $\leq 18$ years, including Crohn's disease (CD) and Ulcerative colitis (UC), at a tertiary children's hospital in Detroit, MI.

\section{Methods}

This was a retrospective, single center cohort study. We included pediatric IBD patients aged $\leq 18$ years who had CDI diagnosed by PCR from the hospital billing system and departmental database from October 1, 2010 - June 30, 2014. IBD was categorized either as $\mathrm{CD}$ or UC. Indeterminate colitis were categorized as per their treatment category either as UC or CD. CDI was defined as presence of symptoms (namely diarrhea) and a positive stool test (PCR) result (9). We excluded patients who were diagnosed outside of our health system to assure PCR as an exclusive method of diagnosis. We defined recurrence of CDI as an episode of CDI that occurs within 8 weeks after the onset of previous episode, provided that symptoms resolved in the interim and repeat PCR testing is positive in similar timeframe (10). Demographic information of patients including age, gender, race and ethnicity were recorded. IBD characteristics, disease location, treatment regimen, use of steroid and biologic therapy at the time of diagnosis of CDI, response to treatment and recurrence were recorded. The study was approved by the Wayne State University Institutional Review Board.

Results

Statistical Analysis

Data were summarized using means, standard deviations and proportions. Comparisons between CD and UC groups were analyzed using a non-parametric Fisher's Exact Chi-square and Mann Whitney U test. Statistical significance was determined by the use of a two tailed test with $\mathrm{p}$-value $\leq 0.05$. All statistical procedures were conducted using SPSS Version 22.0, IBM, Inc.

\section{General and baseline IBD characteristics and treatment}

General characteristics of IBD and patient demographics are summarized in Table 1 . Seventy patients with IBD and CDI were identified. Of these 70 patients, $34 / 70$ patients $(48 \%)$ were inpatients, $32 / 70(46 \%)$ were outpatient, and 4/70 (6\%) were diagnosed in the emergency department (ED). Mean age of initial IBD diagnosis was $13.0 \pm 10.9$ years and current CDI diagnosis was $15.0 \pm 3.7$ years. Of the IBD patients, 43/70 (61\%) had CD and 27/70 (39\%) had UC. Bowel involvement was recorded from biopsy results at the time of initial diagnosis of IBD and not at the time of CDI diagnosis. In regard to primary disease gut involvement prior to CDI, 22 out of 43 (51\%) of CD patients had small and large bowel involvement, 18 with only large bowel (42\%) and 1 with only small bowel $(2 \%)$ involvement. Data on two patients were not available to report for disease location. Out of $27 \mathrm{UC}$ patients, 18 patients $(66 \%)$ had pancolitis and 8 patients $(30 \%)$ had left sided colitis. Information was not available for one patient $(4 \%)$.

Thirty-four of $43 \mathrm{CD}$ patients (79\%) were on 5-aminosalycylic acid derivatives as opposed to $25 / 27(93 \%)$ in UC group. Twenty one patients were receiving biologic treatment $(21 / 70,30 \%)$ including infliximab and adalimumab ( $15 \mathrm{CD}$ vs. $6 \mathrm{UC}$; $\mathrm{p}=0.34)$. In CD patients, 14 were on infliximab $(14 / 43,33 \%)$ and 1 was on adalimumab $(1 / 43,2 \%)$ as opposed to the UC group where 3 patients were on infliximab $(3 / 27,11 \%)$ and 3 were on adalimumab $(3 / 27,11 \%)$. This finding was statistically significant $(\mathrm{p}=0.05)$. Eighteen of 43 patients in the CD group (18/43, 42\%) were on immunomodulator therapy; 13 were on azathioprine $(13 / 18,72 \%)$ and 5 on methotrexate $(5 / 18,28 \%)$. Twelve patients out of 27 in the UC group (44\%) were on immunomodulators including 11 on azathioprine $(11 / 12,92 \%)$ and 1 on methotrexate $(1 / 12,8 \%)$. Demographics, IBD characteristics and treatment with various agents (methotrexate, prednisone, azathioprine and mesalamine) did not vary significantly between IBD groups. 


\begin{tabular}{|c|c|c|c|c|}
\hline & & $\mathrm{CD}$ & UC & $P$ value \\
\hline \multirow[t]{2}{*}{ Sex } & Male & $23(53 \%)$ & $11(41 \%)$ & 0.34 \\
\hline & Female & $20(47 \%)$ & $16(59 \%)$ & \\
\hline \multirow[t]{4}{*}{ Ethnicity } & $\begin{array}{l}\text { African } \\
\text { American }\end{array}$ & $16(37 \%)$ & $8(35 \%)$ & $0.01 \neq$ \\
\hline & Caucasian & $24(56 \%)$ & $10(43 \%)$ & \\
\hline & $\begin{array}{l}\text { Middle } \\
\text { Eastern }\end{array}$ & $3(7 \%)$ & $3(13 \%)$ & \\
\hline & Asian & $0(0 \%)$ & $2(9 \%)$ & \\
\hline \multirow[t]{2}{*}{ Mesalamine } & No & $9(21 \%)$ & $9(35 \%)$ & 0.38 \\
\hline & Yes & $33(79 \%)$ & $17(65 \%)$ & \\
\hline \multirow[t]{2}{*}{ Sulphasalazine } & No & $41(98 \%)$ & $19(70 \%)$ & 0.002 \\
\hline & Yes & $1(2 \%)$ & $8(30 \%)$ & \\
\hline \multirow[t]{2}{*}{ Biologics } & infliximab & $14(93 \%)$ & $3(50 \%)$ & 0.05 \\
\hline & adalimumab & $1(7 \%)$ & $3(50 \%)$ & \\
\hline \multirow[t]{2}{*}{ Immunomodulator } & No & $23(56 \%)$ & $15(56 \%)$ & 1.00 \\
\hline & Yes & $18(44 \%)$ & $12(44 \%)$ & \\
\hline \multirow{2}{*}{$\begin{array}{l}\text { Type of immunomod- } \\
\text { ulator }\end{array}$} & methotrexate & $5(28 \%)$ & $1(8 \%)$ & 0.46 \\
\hline & azathioprine & $13(72 \%)$ & $11(92 \%)$ & \\
\hline \multirow{3}{*}{$\begin{array}{l}\text { Hospitalizations in } \\
\text { last } 5 \text { years }\end{array}$} & $\leq 3$ & $29(67 \%)$ & $20(74 \%)$ & $0.92 \neq$ \\
\hline & $4-8$ & $10(23 \%)$ & $5(19 \%)$ & \\
\hline & $>8$ & $4(10 \%)$ & $2(7 \%)$ & \\
\hline
\end{tabular}

Denominators have been changed where one or more variables were unavailable to report Abbreviations: IBD: Inflammatory bowel disease; CD: Crohn's Disease; UC: Ulcerative Colitis. $\neq$ Overall comparison $P$ value 
CDI: Disease and treatment characteristics and recurrence

In CD group, 21 of 41 (51\%) patients had symptoms of CDI for 1 week or less, $15 / 41(37 \%)$ for $1-2$ week and 5/41 (12\%) for greater than 2 weeks prior to their formal stool PCR test. For the UC group, these numbers were $15 / 27$ (56\%), 10/27 (37\%) and 2/43 (7\%) respectively. The main presentation of CDI was abdominal cramping and diarrhea, with or without gross bleeding. Majority of patients in both groups (32/43, 74\% in CD and $21 / 27,78 \%$ in UC) presented without nausea or vomiting. A higher proportion of CDI in CD patients 28/43 (65\%) did not have gross blood noted in the stool compared to $11 / 27(41 \%)$ UC patients $(\mathrm{p}=0.05)$.

Sixty-four out of $70(91 \%)$ patients received metronidazole as first line treatment. Five patient received vancomycin as first line treatment with good response. Data on one patient was unavailable to report. Majority of patients, 56/64 (88\%), were treated for 1-2 weeks. Six patients $(6 / 64,9 \%)$ were treated for $2-3$ weeks and 2 patients $(2 / 64,3 \%)$ were on treatment for more than 3 weeks. A favorable response to initial metronidazole treatment occurred in $58(58 / 64,90 \%)$ patients. A total of six patients $(6 / 64,9 \%)$ did not respond to initial treatment of metronidazole. We termed them as a 'nonresponders' since those patients did not have interim resolutions of symptoms so could not be defined as recurrence. All nonresponders were treated with oral vancomycin and 5 out of 6 $(83 \%)$ responded. One patient $(17 \%)$ needed vancomycin with a taper for greater than 3 months and eventually responded with prolonged treatment. CDI treatment agent did not vary to a statistical significance between the groups.

Although not a common practice, some patients had repeat PCR testing and were found to have negative PCR in 21/70 (30 \%) patients. Most patients did not have repeat PCR testing (48/70, 69\%). Information on one patient was not available.
Out of our cohort, 8 of 70 patients $(11 \%)$ had recurrence $(3 \mathrm{CD}$ and 5 UC) within 8 weeks with interim resolution of symptomatology. Thirteen patients (19\%, 8 CD and 5 UC) had a new CDI episode after 8 weeks. Out of these 13 patients, 4 were treated with a repeat metronidazole course, 8 were treated with oral vancomycin and 1 patient required vancomycin with a tapering dose. That particular patient had multiple relapses later on and subsequently was treated with a vancomycin tapering treatment and fidaxomicin and eventually responded. Out of these 13 patients with new CDI, 12 responded on repeat treatment while one was lost to follow up. This patient was counted as failure of treatment in analyzing data. There was no mortality recorded secondary to CDI in our cohort. CDI presentation, treatment and recurrence characteristics are summarized in Table 2, 3 and 4 respectively.

\section{Risk Factor}

Out of $43,29 \mathrm{CD}$ patients $(67 \%)$ had 3 or less hospitalizations in the prior 5 years, $10(23 \%)$ had hospitalizations 4 to 8 times and 4 patients $(10 \%)$ had more than 8 hospitalizations. Out of $27 \mathrm{UC}$ patients, 20 patients $(74 \%)$ had 3 or fewer hospitalizations in last 5 years, 5 patients $(19 \%)$ had 4 to 8 hospitalizations and 2 patients (7\%) had more than 8 hospitalizations. In the CD group, 36/43 (84\%) and in UC group, 23/27 (85\%) did not have documented use of any systemic antibiotic in last 3 months prior to the date of CDI diagnosis. Antibiotic use, steroid treatment and the number of prior hospitalizations were not significantly different between IBD groups. Most of CD (28/43, 65\%) and UC (19/26, 73\%) patients were not on steroid treatment at the time of CDI diagnosis. Only 15 patients out of 43 in the CD group (15/43,35\%) and 7 of 26 patients in the UC group (7/26, 27\%) were on steroids. Information on 1 UC patients was not available. Steroid use was not statistically significant between the groups. Co-morbid conditions associated with these patients are summarized in Table 5. 
Dhiren Patel et.al (2017). Clostridium difficile Infection in Pediatric Inflammatory Bowel Disease Patients in the Era of Molecular Diagnostics and Advanced Therapeutics. Int J Ped \& Neo Heal. 1:4, 105-115

\begin{tabular}{|c|c|c|c|c|}
\hline & & $\mathrm{CD}$ & $\mathrm{UC}$ & P Value \\
\hline \multirow[t]{2}{*}{ Vomiting at presentation } & No & $32(74 \%)$ & $21(78 \%)$ & 1.00 \\
\hline & Yes & $11(26 \%)$ & $6(22 \%)$ & \\
\hline \multirow[t]{2}{*}{ Diarrhea } & No & $8(19 \%)$ & $2(8 \%)$ & 0.29 \\
\hline & Yes & $35(81 \%)$ & $25(92 \%)$ & \\
\hline \multirow[t]{2}{*}{ Blood in stool } & No & $28(65 \%)$ & $11(41 \%)$ & 0.05 \\
\hline & Yes & $15(35 \%)$ & $16(59 \%)$ & \\
\hline \multirow[t]{2}{*}{ Fever } & No & $39(91 \%)$ & $24(89 \%)$ & 1.00 \\
\hline & Yes & $4(9 \%)$ & $3(11 \%)$ & \\
\hline \multirow[t]{2}{*}{ Abdominal pain } & No & $3(7 \%)$ & $1(4 \%)$ & 1.00 \\
\hline & Yes & $40(93 \%)$ & $26(96 \%)$ & \\
\hline \multirow[t]{3}{*}{ CDI Diagnosis site } & Inpatient & $20(46 \%)$ & $14(52 \%)$ & $0.38 \neq$ \\
\hline & Outpatient & $19(44 \%)$ & $13(48 \%)$ & \\
\hline & ED & $4(10 \%)$ & $0(0 \%)$ & \\
\hline \multirow{2}{*}{$\begin{array}{l}\text { Systemic antibiotics use } \\
\text { in last } 3 \text { months }\end{array}$} & No & $36(84 \%)$ & $23(85 \%)$ & 1.00 \\
\hline & Yes & $7(16 \%)$ & $4(15 \%)$ & \\
\hline \multirow[t]{2}{*}{ Duration of symptoms } & $\leq 1$ week & $21(51 \%)$ & $15(56 \%)$ & $0.77 \neq$ \\
\hline & $1-2$ weeks & $15(37 \%)$ & $10(37 \%)$ & \\
\hline \multirow{2}{*}{$\begin{array}{l}\text { On steroid at CDI diag- } \\
\text { nosis }\end{array}$} & No & $28(65 \%)$ & $19(73 \%)$ & 0.59 \\
\hline & Yes & $15(35 \%)$ & $7(27 \%)$ & \\
\hline
\end{tabular}

Denominators have been changed where one or more variables were unavailable to report

Abbreviations: CD Crohn's disease, UC ulcerative colitis, CDI Clostridium difficile infection, ED emergency department $\neq$ Overall comparison $P$ value 
Dhiren Patel et.al (2017). Clostridium difficile Infection in Pediatric Inflammatory Bowel Disease Patients in the Era of Molecular Diagnostics and Advanced Therapeutics. Int J Ped \& Neo Heal. 1:4, 105-115

\begin{tabular}{|c|c|c|c|c|}
\hline & & $\mathrm{CD}$ & $\mathrm{UC}$ & P Value \\
\hline \multirow[t]{4}{*}{ Treatment } & metronidazole oral & $34(81 \%)$ & $25(93 \%)$ & $0.21 \neq$ \\
\hline & $\begin{array}{l}\text { metronidazole intrave- } \\
\text { nous then changed to oral }\end{array}$ & $5(12 \%)$ & $0(0 \%)$ & \\
\hline & $\begin{array}{l}\text { vancomycin without } \\
\text { taper }\end{array}$ & $2(5 \%)$ & $2(7 \%)$ & \\
\hline & vancomycin with taper & $1(2 \%)$ & $0(0 \%)$ & \\
\hline \multirow[t]{3}{*}{ Duration of treatment } & 1-2 weeks & $36(90 \%)$ & $20(83 \%)$ & $0.25 \neq$ \\
\hline & 2-3 weeks & $2(5 \%)$ & $4(17 \%)$ & \\
\hline & More than $3 \mathrm{wk}$ & $2(5 \%)$ & $0(0 \%)$ & \\
\hline \multirow{2}{*}{$\begin{array}{l}\text { Improved diarrhea after } \\
\text { treatment }\end{array}$} & No & $4(11 \%)$ & $9(35 \%)$ & 0.023 \\
\hline & Yes & $34(89 \%)$ & $17(65 \%)$ & \\
\hline \multirow[t]{2}{*}{$\begin{array}{l}\text { Improved abdominal } \\
\text { pain }\end{array}$} & No & $4(10 \%)$ & $7(27 \%)$ & 0.11 \\
\hline & Yes & $35(90 \%)$ & $19(73 \%)$ & \\
\hline
\end{tabular}

Denominators have been changed where one or more variables were unavailable to report Abbreviations: CD Crohn's disease, UC ulcerative colitis, CDI Clostridium difficile infection $\neq$ Overall comparison $P$ value 
Dhiren Patel et.al (2017). Clostridium difficile Infection in Pediatric Inflammatory Bowel Disease Patients in the Era of Molecular

Diagnostics and Advanced Therapeutics. Int J Ped \& Neo Heal. 1:4, 105-115

\begin{tabular}{|c|c|c|c|c|}
\hline & & $\mathrm{CD}$ & $\mathrm{UC}$ & $\mathrm{P}$ value \\
\hline \multirow[t]{2}{*}{ Recurrence } & No & $40(93 \%)$ & $22(81 \%)$ & 0.24 \\
\hline & Yes & $3(7 \%)$ & $5(19 \%)$ & \\
\hline \multirow[t]{2}{*}{ Vomiting at recurrence } & No & $3(100 \%)$ & $4(80 \%)$ & 1.00 \\
\hline & Yes & $0(0 \%)$ & $1(20 \%)$ & \\
\hline \multirow{2}{*}{$\begin{array}{l}\text { Blood in stool at recur- } \\
\text { rence }\end{array}$} & No & $2(67 \%)$ & $1(20 \%)$ & 0.46 \\
\hline & Yes & $1(33 \%)$ & $4(80 \%)$ & \\
\hline \multirow[t]{2}{*}{ Fever at recurrence } & No & $3(100 \%)$ & $4(80 \%)$ & 1.00 \\
\hline & Yes & $0(0 \%)$ & $1(20 \%)$ & \\
\hline \multirow{2}{*}{$\begin{array}{l}\text { Abdominal pain at recur- } \\
\text { rence }\end{array}$} & No & $0(0 \%)$ & $1(20 \%)$ & 1.00 \\
\hline & Yes & $3(100 \%)$ & $4(80 \%)$ & \\
\hline \multirow[t]{3}{*}{ Treatment of recurrence } & metronidazole oral & $1(33 \%)$ & $2(40 \%)$ & $1.00 \neq$ \\
\hline & vancomycin without taper & $1(33 \%)$ & $1(20 \%)$ & \\
\hline & vancomycin with taper & $1(33 \%)$ & $2(40 \%)$ & \\
\hline \multirow{2}{*}{$\begin{array}{l}\text { Duration of recurrence } \\
\text { treatment }\end{array}$} & 2-3 weeks & $1(50 \%)$ & $2(66 \%)$ & 1.00 \\
\hline & More than 3 weeks & $1(50 \%)$ & $1(33 \%)$ & \\
\hline \multirow{2}{*}{$\begin{array}{l}\text { Response to treatment for } \\
\text { recurrence }\end{array}$} & No & $0(0 \%)$ & $1(20 \%)$ & 1.00 \\
\hline & Yes & $3(100 \%)$ & $4(80 \%)$ & $0.28 \neq$ \\
\hline \multirow[t]{3}{*}{ PCR after recurrence } & Negative & $1(33 \%)$ & $0(0 \%)$ & \\
\hline & Positive & $1(33 \%)$ & $1(20 \%)$ & \\
\hline & Not tested & $1(33 \%)$ & $4(80 \%)$ & \\
\hline \multirow{2}{*}{$\begin{array}{l}\text { Improved diarrhea after } \\
\text { treatment of recurrence }\end{array}$} & No & $0(0 \%)$ & $1(20 \%)$ & 1.00 \\
\hline & Yes & $3(100 \%)$ & $4(80 \%)$ & \\
\hline \multirow{2}{*}{$\begin{array}{l}\text { Improved } \\
\text { abdominal pain after } \\
\text { recurrence treatment }\end{array}$} & No & $0(0 \%)$ & $1(20 \%)$ & 1.00 \\
\hline & Yes & $3(100 \%)$ & $4(80 \%)$ & \\
\hline
\end{tabular}

Denominators have been changed where one or more variables were unavailable to report

Abbreviations: CD Crohn's disease, UC ulcerative colitis, CDI Clostridium difficile infection, ED emergency department, PCR- polymerase chain reaction

$\neq$ Overall comparison $P$ value 


\begin{tabular}{|l|l|}
\hline Co morbidity & N ( \%) total patients- 70 \\
\hline Anemia & $12(17 \%)$ \\
\hline IBD with strictures & $3 \quad(4 \%)$ \\
\hline IBD with fistulas and abscess & $10(14 \%)$ \\
\hline Neutropenia & $1 \quad(1 \%)$ \\
\hline Polyposis & $1 \quad(1 \%)$ \\
\hline Pancreatitis & $2 \quad(3 \%)$ \\
\hline History of colectomy and ileoanal pouch & $3 \quad(4 \%)$ \\
\hline
\end{tabular}

IBD: Inflammatory Bowel Disease; $\mathbf{N}=$ number of patients having co-morbid condition

\section{Discussion}

As a regional referral center providing tertiary care, our IBD patient population is comprised of over 450 patients who are followed at our pediatric IBD center. In this study, we analyzed characteristics of IBD patients with CDI along with other variables. In our study, CD patients with CDI who were on infliximab treatment were significantly greater in proportion than UC patients on infliximab. The safety of biologic agents for IBD treatment in pediatric patients remains a concern. Due to lack of pediatric studies, all current data were abstracted from adult IBD studies. One study in the literature did suggest that mortality rates were similar between IBD patients treated with infliximab versus those who were treated with other treatment modalities (11). This study also concluded that the risk of severe bacterial infection observed with biologic therapy was due to disease severity and concomitant corticosteroid use rather than infliximab therapy alone. On the contrary, another study suggested that infliximab use was associated with an increased risk of infection, most commonly histoplasmosis, and the risk of infection was increased when infliximab is used in combination with corticosteroid and azathioprine/6-mercaptopurines (12) . In an adult randomized, placebo-controlled trial of rheumatoid arthritis patients with comorbidities receiving infliximab, serious bacterial infections were 3 times more likely to occur in the treatment arm compared to placebo patients (13). All of these studies were primarily adult studies and CDI was not mentioned as an opportunistic infection. One adult study concluded no increased rate of serious bacterial infection in IBD patients on biologic (infliximab) therapy, including CDI, although the risk of CDI was increased by three times with corticosteroid use (14). This study primarily included adult CDI patients who required inpatient hospitalizations and excluded outpatient CDI diagnosis to overcome technical difficulties in analysis. In our study, the analysis included all patients diagnosed with a positive stool PCR during inpatient, outpatient or ED visits.

Thus far, no specific study has reported a CDI risk associated with the use of a specific type of biologic in the pediatric IBD population and this will need further study. A higher proportion of CDI in a specific biologic group could possibly be due to the immunosuppressive effect on gut. A randomized placebo controlled trial for immune mechanisms and risk of CDI in IBD patients who are receiving biologic treatment is needed.

Adult studies have shown likely association between the risk of CDI and IBD treatments such as mesalamine, steroids, azathioprine and methotrexate $(3,15)$. Our study was aimed at children and adolescents and did not find a difference in the proportion between the groups with CDI in pediatric IBD patients receiving these therapies. In a pediatric study by Martinelli et al, previous hospitalizations were noted more frequently in patients with IBD without CDI than in patients with IBD with CDI (1). In a retrospective adult study, two or more inpatient hospitalizations within 60 days prior to the onset of CDI was associated with an increased risk of recurrent CDI (16). In our study, we found no significant difference between both groups. Antibiotic use within the past 3 months prior to CDI was not statistically significant between groups in our cohort, unlike the result of a prior adult study (17). We observed that only one patient in CD group with small bowel involvement had CDI. This also support the data from various studies that concluded UC and Crohn's colitis patients are more at risk to have extensive CDI than isolated CD small bowel involvement (3) (18) (19) .

Most patients responded to therapy with a 10-14 day course of conventional metronidazole therapy in our study, which is suggestive of continued efficacy of metronidazole in initial therapy for CDI even in IBD patients (20). Only a few patients who relapsed re- 
quired vancomycin therapy either for 2 weeks or as a taper course. Although ours was a pediatric study, we found a similar result to a report from an adult systematic review which concluded that both vancomycin and metronidazole could be the first choice of treatment and thus depends primarily on underlying CDI severity (21) . The literature suggests that the incidence of CDI is higher in IBD patients (3) and that CDI can present with nonbloody stools, as was noted in our cohort. In our study, most of patients with CDI and IBD presented without blood in the stool. This was a statistically significant observation between our groups as fewer CD patients had blood in their stool compared to UC patients $(\mathrm{p}=0.05)$. This finding requires further study.

\section{Limitations}

This was a retrospective single-center descriptive cohort study which did not have a case control group for comparison. For the same reason, we could not report incidence of CDI in pediatric IBD population at our center. Statistically significant differences in demographic and patient characteristics are explained by known differences between the study groups; as an example, UC patients, by definition, have specific large bowel involvement. Therefore UC patients had a higher proportion of this variable when compared to $\mathrm{CD}$, which may involve any portion of the gut. We used subjective definitions to identify CDI case and response to treatment. As this was a chart review, data captured is subject to incomplete medical records and, in some cases; we could not report all the parameters of our interest. Because of the higher sensitivity of PCR testing, repeat PCR testing could over diagnose the same strain of infection and may not represent a true recurrence. As we exclusively used patients with PCR diagnosis of CDI, this was not a comparison study of toxin versus PCR detection methods for CDI diagnosis in this population.

\section{Conclusion}

CDI should be considered in the evaluation of pediatric patients with IBD flare up. In pediatric IBD patients, the absence of blood in stool does not rule out CDI. Most patients responded to initial therapy with metronidazole in both groups. A statistically significant higher proportion of $\mathrm{CD}$ patients on infliximab therapy with CDI were identified as compared to UC patients with CDI on infliximab. Future prospective studies are needed to determine if treatment with specific biologic agent is associated with a true increased risk of CDI in pediatric IBD patients.

References

1. Martinelli M, Strisciuglio C, Veres G, Paerregaard A, Pavic AM, Aloi M, et al. Clostridium difficile and pediatric inflammatory bowel disease: a prospective, comparative, multicenter, ESPGHAN study. Inflamm Bowel Dis. 2014;20(12):2219-25. Epub 2014/10/01. doi: 10.1097/mib.0000000000000219. PubMed PMID: 25268634.

2. Berg AM, Kelly CP, Farraye FA. Clostridium difficile infection in the inflammatory bowel disease patient. Inflamm Bowel Dis. 2013;19(1):194-204. Epub 2012/04/18. doi: 10.1002/ibd.22964. PubMed PMID: 22508484.

3. Rodemann JF, Dubberke ER, Reske KA, Seo da H, Stone CD. Incidence of Clostridium difficile infection in inflammatory bow- el disease. Clin Gastroenterol Hepatol. 2007;5(3):339-44. Epub 2007/03/21. doi: 10.1016/j.cgh.2006.12.027. PubMed PMID: 17368233 .

4. Mezoff E, Mann EA, Hart KW, Lindsell CJ, Cohen MB. Clostridium difficile infection and treatment in the pediatric inflammatory bowel disease population. J Pediatr Gastroenterol Nutr. 2011;52(4):437-41. Epub 2011/03/17. doi: 10.1097/ MPG.0b013e3181f97209. PubMed PMID: 21407116; PubMed Central PMCID: PMCPMC3075442.

5. Poutanen SM, Simor AE. Clostridium difficile-associated diarrhea in adults. CMAJ. 2004;171(1):51-8. Epub 2004/07/09. PubMed PMID: 15238498; PubMed Central PMCID: PMCPMC437686.

6.Severe Clostridium difficile-associated disease in populations previously at low risk--four states, 2005. MMWR Morb Mortal Wkly Rep. 2005;54(47):1201-5. Epub 2005/12/02. PubMed PMID: 16319813.

7. Pascarella F, Martinelli M, Miele E, Del Pezzo M, Roscetto E, Staiano A. Impact of Clostridium difficile infection on pediatric inflammatory bowel disease. J Pediatr. 2009;154(6):854-8. Epub 2009/02/24. doi: 10.1016/j.jpeds.2008.12.039. PubMed PMID: 19230908 .

8. Kvach EJ, Ferguson D, Riska PF, Landry ML. Comparison of BD GeneOhm Cdiff real-time PCR assay with a two-step algorithm and a toxin $\mathrm{A} / \mathrm{B}$ enzyme-linked immunosorbent assay for diagnosis of toxigenic Clostridium difficile infection. J Clin Microbiol. 2010;48(1):109-14. Epub 2009/10/30. doi: 10.1128/ jcm.01630-09. PubMed PMID: 19864479; PubMed Central PMCID: PMCPMC2812270.

9. Cohen SH, Gerding DN, Johnson S, Kelly CP, Loo VG, McDonald LC, et al. Clinical practice guidelines for Clostridium difficile infection in adults: 2010 update by the society for healthcare epidemiology of America (SHEA) and the infectious diseases society of America (IDSA). Infect Control Hosp Epidemiol. 2010;31(5):431-55. Epub 2010/03/24. doi: 10.1086/651706. PubMed PMID: 20307191.

10.McDonald LC, Coignard B, Dubberke E, Song X, Horan T, Kutty PK, et al. Recommendations for surveillance of Clostridium difficile-associated disease. Infection control and hospital epidemiology. 2007;28(2):140-5. doi: 10.1086/511798. PubMed PMID: 17265394.

11. Lichtenstein GR, Feagan BG, Cohen RD, Salzberg BA, Diamond RH, Price S, et al. Serious infection and mortality in patients with Crohn's disease: more than 5 years of follow-up in the TREAT registry. Am J Gastroenterol. 2012;107(9):1409-22. Epub 2012/08/15. doi: 10.1038/ajg.2012.218. PubMed PMID: 22890223; PubMed Central PMCID: PMCPMC3438468.

12. Toruner M, Loftus EV, Jr., Harmsen WS, Zinsmeister AR, Orenstein R, Sandborn WJ, et al. Risk factors for opportunistic infections in patients with inflammatory bowel disease. Gastroenterology. 2008;134(4):929-36. Epub 2008/02/26. doi: 10.1053/j. gastro.2008.01.012. PubMed PMID: 18294633.

13. Westhovens R, Yocum D, Han J, Berman A, Strusberg I, Geusens $\mathrm{P}$, et al. The safety of infliximab, combined with background treatments, among patients with rheumatoid arthritis and vari- 
ous comorbidities: a large, randomized, placebo-controlled trial. Arthritis Rheum. 2006;54(4):1075-86. Epub 2006/03/31. doi: 10.1002/art.21734. PubMed PMID: 16572442.

14. Schneeweiss S, Korzenik J, Solomon DH, Canning C, Lee $\mathrm{J}$, Bressler B. Infliximab and other immunomodulating drugs in patients with inflammatory bowel disease and the risk of serious bacterial infections. Aliment Pharmacol Ther. 2009;30(3):25364. Epub 2009/05/15. doi: 10.1111/j.1365-2036.2009.04037.x.
PubMed PMID: 19438424.

15. Viget N, Vernier-Massouille G, Salmon-Ceron D, Yazdanpanah Y, Colombel JF. Opportunistic infections in patients with inflammatory bowel disease: prevention and diagnosis. Gut. 2008;57(4):549-58. Epub 2008/01/08. doi: 10.1136/ gut.2006.114660. PubMed PMID: 18178610.

16. Zilberberg MD, Reske K, Olsen M, Yan Y, Dubberke ER. Risk factors for recurrent Clostridium difficile infection (CDI) hospital 